\title{
Características de frutos de pessegueiros cultivados na Zona da Mata de Minas Gerais
}

\author{
Characteristics of peach fruits grown in the Zona da Mata of Minas Gerais, Brazil
}

\author{
Rosana Gonçalves Pires Matias ${ }^{I}$ Danielle Fabíola Pereira da Silva ${ }^{I I}$ \\ Mariana Rodrigues Ribeiro III José Osmar da Costa e Silva ${ }^{\text {II }}$ \\ Silvia Paula de Oliveira ${ }^{\mathrm{III}}$ Cláudio Horst Bruckner ${ }^{\mathrm{II}}$
}

\section{- NOTA -}

RESUMO

Este trabalho teve como objetivo avaliar características físicas e químicas de frutos de 13 cultivares de pessegueiro de polpa amarela introduzidas no pomar experimental da Universidade Federal de Viçosa (UFV), Viçosa-MG. O experimento foi conduzido durante a safra 2011, em delineamento inteiramente casualisado, com 13 tratamentos (cultivares), três repetições e 10 frutos por parcela. As cultivares 'Cerrito', 'Minasul' e 'Olímpia' apresentaram, no geral, maior peso e diâmetros de frutos. Os frutos das cultivares 'Belvedere', 'Coral', 'Rubimel' e 'Talismã' apresentaram melhor balanço entre sólidos solúveis e acidez. Maiores teores de vitamina $C$ e de carotenoides foram encontrados nos frutos das cultivares 'Baronesa' e 'Flordaprince' e de 'Aldrigui'e 'Elberta', respectivamente.

Palavras-chave: Prunus persica, adaptação, qualidade de fruto.

\section{ABSTRACT}

This study aimed to evaluate physical and chemical characteristics of fruits of 13 peach cultivars with yellow flesh introduced in the experimental orchard of the Federal University of Viçosa (UFV), Viçosa-MG. The experiment was conducted during the 2011 season, in a completely randomized design with 13 treatments (cultivars), three replicates of 10 fruits per plot. The fruits of cultivars 'Cerrito', 'Minasul' and 'Olímpia' had , in general, higher fruit weight and diameter. The fruits of cultivars 'Belvedere', 'Coral', 'Rubimel' and 'Talismã' had a better balance between acidity and soluble solids. Higher levels of vitamin $C$ and carotenoids were found in the fruits of cultivars 'Baronesa' and 'Flordaprince' and of 'Aldrigui' and 'Elberta', respectively.

Key words: Prunus persica, adaptation, fruit quality.
O conhecimento da capacidade de adaptação das cultivares de pessegueiro (Prunus persica L. Bastch) a determinada região é muito importante, pois, através dele, é possível tomar decisões como época e tipos de poda a serem realizadas, uso de reguladores de crescimento vegetal e, com isso, possibilitar que a cultura expresse seu máximo potencial produtivo (LEONEL et al., 2011).

O pessegueiro é uma planta típica de clima temperado. No entanto, a região Sudeste, em locais de clima ameno, apresenta boas condições para a exploração econômica de fruteiras de clima temperado, devido principalmente à elevada altitude (RAMOS \& LEONEL, 2008). Verifica-se que, em consequência do melhoramento genético, a expansão da fruticultura de clima temperado vem avançando, progressivamente, com sucesso econômico (LEONEL et al., 2011).

As peculiaridades de sabor e aroma do pêssego resultam do equilíbrio de açúcares, ácidos orgânicos, compostos fenólicos, carotenoides e compostos voláteis, características que levam essa fruta a ser muito apreciada e de grande importância comercial, incluindo "commodities" derivadas da cadeia produtiva (GIL et al., 2002). Todavia, as informações sobre as características físicas e químicas dos frutos de pêssegos na região da Zona da Mata mineira são incipientes, embora sejam importantes para orientação dos produtores sobre quais variedades devem ser escolhidas para o plantio. Este trabalho

'Programa de Pós-graduação em Genética e Melhoramento, Departamento de Fitotecnia, Universidade Federal de Viçosa (UFV), 36570-000, Viçosa, MG, Brasil. E-mail: rosana.pires@ufv.br. Autor para correspondência.

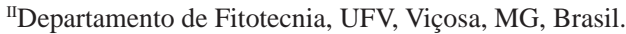

IIICurso de Agronomia, Departamento de Fitotecnia, UFV, Viçosa, MG, Brasil. 
teve como objetivo avaliar características físicas e químicas de 13 cultivares de pessegueiro de polpa amarela na Zona da Mata mineira.

O estudo foi realizado durante a safra de 2011, com 13 cultivares de pessegueiro de polpa amarela ('Aldrigui', 'Argel', 'Baronesa', 'Belvedere', 'Cerrito', 'Coral', Elberta, 'Flordaprince', 'Minasul', 'Olímpia', ‘Rubimel’, ‘Talismã' e 'Topázio’). As plantas, enxertadas sobre o porta-enxerto 'Okinawa', têm aproximadamente 3,5 anos e pertencem ao pomar experimental da Universidade Federal de Viçosa (UFV), Viçosa-MG (2045'S e 4251'O; 649m de altitude).

Os frutos foram colhidos usando como critério a mudança da coloração de fundo de verde para amarelo-claro e avaliados quanto às características: massa do fruto (MF), em gramas (g); diâmetro longitudinal (DL) e diâmetro transversal (DT), em mm; firmeza da polpa (FIR), em N; teor de sólidos solúveis (SS), em ${ }^{\circ}$ Brix; acidez titulável (AT), em \% de ácido málico; teor de ácido ascórbico (Vit C), de acordo com metodologia descrita em AOAC (1997), sendo os resultados expressos em mg de ácido ascórbico por 100g de polpa; “ratio”, dado pela relação entre o teor de sólidos solúveis e a acidez titulável (SS/AT); e carotenoides totais (CT), em mg $100 \mathrm{~g}^{-1}$ de polpa, determinados segundo as equações de LICHTENTHALER (1987).

Foi usado o delineamento inteiramente casualizado, com 13 tratamentos (variedades), três repetições e dez frutos por parcela. Foram utilizadas três plantas por variedade e em cada uma foram colhidos dez frutos, totalizando 30 frutos por variedade. Os dados obtidos foram submetidos à análise de variância e as médias comparadas pelo teste Scott-Knott em nível de 5\% de probabilidade. As análises foram realizadas com o auxílio do aplicativo computacional GENES - versão 2007 (CRUZ, 2006).

A massa dos frutos variou de 57,83g ('Talismã') a 99,51g ('Olímpia') (Tabela 1). ALBUQUERQUE et al. (2000), avaliando cultivares de pessegueiro e nectarineira em Araponga-MG, obtiveram frutos com massa variando de 33,29 a 78,48g e observaram que a cultivar 'Talismã' apresentou frutos com massa média de 48,88g, menor que a obtida neste trabalho $(57,83 \mathrm{~g})$.

As cultivares 'Cerrito', 'Minasul' e 'Olímpia' apresentaram frutos com os maiores diâmetros longitudinais (comprimento), com 61,47, 59,05 e $62,09 \mathrm{~mm}$, respectivamente, e a cultivar 'Argel' com o menor $(47,77 \mathrm{~mm})$. Já quanto ao diâmetro transversal, a variação foi um pouco menor, em que o maior diâmetro foi de 56,89mm ('Olímpia') e o menor de 45,82mm ('Talismã') (Tabela 1). MONTES et al. (2008), avaliando frutos de cultivares de pessegueiro enxertados sobre dois porta-enxertos no oeste do Estado de São Paulo, observaram que a cultivar 'Talismã' sobre o porta-enxerto 'Okinawa' foi a que apresentou os frutos de maior comprimento.

Frutos da cultivar 'Flordaprince' tiveram firmeza de polpa maior do que as demais $(74,58 \mathrm{~N})$, não diferindo significativamente de 'Baronesa' $(68,24 \mathrm{~N})$. Cultivares cujos frutos são mais firmes apresentam potencial pós-colheita em relação a esta característica, uma vez que, segundo WAGNER JÚNIOR et al.

Tabela 1- Massa de fruto (MF), diâmetro longitudinal (DL), diâmetro transversal (DT), firmeza de polpa (FIR), teor de sólidos solúveis (SS), acidez titulável (AT), "ratio" (SS/AT), teor de ácido ascórbico (Vit C) e carotenoides totais (CT) de frutos de 14 cultivares de pessegueiro de polpa amarela colhidos na região da Zona da Mata mineira. Viçosa, UFV, 2011.

\begin{tabular}{|c|c|c|c|c|c|c|c|c|c|}
\hline Variedades & $\begin{array}{l}\text { MF } \\
\text { (g) }\end{array}$ & $\begin{array}{c}\mathrm{DL} \\
(\mathrm{mm})\end{array}$ & $\begin{array}{c}\mathrm{DT} \\
(\mathrm{mm})\end{array}$ & $\begin{array}{l}\text { FIR } \\
(\mathrm{N})\end{array}$ & $\begin{array}{c}\text { SS } \\
\left({ }^{\circ} \text { Brix }\right)\end{array}$ & $\begin{array}{l}\text { AT } \\
(\%)\end{array}$ & $\begin{array}{c}\text { Ratio } \\
\text { (SS/AT) }\end{array}$ & $\begin{array}{c}\text { Vit C } \\
\left(\mathrm{mg} \mathrm{100g}^{-1}\right)\end{array}$ & 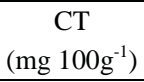 \\
\hline Aldrigui & $77,41 b$ & $54,03 b$ & $51,08 b$ & $44,14 \mathrm{c}$ & $11,54 \mathrm{c}$ & $0,72 \mathrm{a}$ & $16,30 \mathrm{~b}$ & $7,58 \mathrm{c}$ & $1,40 \mathrm{a}$ \\
\hline Argel & $59,77 \mathrm{c}$ & $47,77 d$ & $47,16 \mathrm{c}$ & $25,46 \mathrm{~d}$ & $11,43 c$ & $0,74 a$ & $15,73 b$ & $7,80 \mathrm{c}$ & $0,47 f$ \\
\hline Baronesa & $84,55 b$ & $54,22 b$ & $51,88 b$ & $68,24 a$ & $9,85 e$ & $0,86 a$ & $11,66 b$ & $18,83 a$ & $0,34 \mathrm{f}$ \\
\hline Belvedere & $75,65 b$ & $54,86 b$ & $50,19 b$ & $51,78 b$ & $10,30 d$ & $0,43 b$ & $25,56 a$ & $8,83 c$ & $0,43 f$ \\
\hline Cerrito & $90,37 a$ & $61,47 a$ & $53,05 b$ & $57,22 b$ & $11,97 b$ & $0,86 a$ & $14,20 b$ & $9,98 c$ & $0,98 c$ \\
\hline Coral & $63,66 c$ & $51,65 c$ & $47,47 \mathrm{c}$ & $56,44 b$ & $10,05 \mathrm{e}$ & $0,44 b$ & $23,15 a$ & $9,52 \mathrm{c}$ & $0,33 f$ \\
\hline Elberta & $84,84 b$ & $55,88 b$ & $53,92 a$ & $34,60 d$ & $11,45 \mathrm{c}$ & $0,69 a$ & $16,86 b$ & $9,24 c$ & $1,18 b$ \\
\hline Flordaprince & $84,64 b$ & $53,88 b$ & $50,54 b$ & $74,58 a$ & $10,46 \mathrm{~d}$ & $0,72 \mathrm{a}$ & $15,19 b$ & $19,47 a$ & $0,45 f$ \\
\hline Minasul & 96,73a & 59,05a & 56,03a & 33,62d & $12,60 \mathrm{a}$ & $0,75 a$ & $17,14 b$ & 8,33c & $0,85 c$ \\
\hline Olímpia & $99,51 \mathrm{a}$ & $62,09 a$ & $56,89 a$ & $44,22 c$ & $11,52 \mathrm{c}$ & $0,60 \mathrm{a}$ & $19,43 b$ & $9,80 \mathrm{bc}$ & 0,69d \\
\hline Rubimel & $87,13 b$ & $53,81 b$ & $53,12 b$ & $45,38 c$ & $9,77 \mathrm{e}$ & $0,41 b$ & $25,42 \mathrm{a}$ & $9,01 c$ & $0,55 \mathrm{e}$ \\
\hline Talismã & $57,83 c$ & $50,70 \mathrm{c}$ & $45,82 c$ & $62,42 b$ & $11,72 \mathrm{c}$ & $0,62 \mathrm{a}$ & $20,96 a$ & $13,94 b$ & $0,40 \mathrm{f}$ \\
\hline Topázio & $64,57 \mathrm{c}$ & $56,23 b$ & $46,36 c$ & $61,89 b$ & $12,01 b$ & $0,76 a$ & $18,42 b$ & $9,35 c$ & $0,51 \mathrm{e}$ \\
\hline
\end{tabular}

Médias seguidas de mesma letra na coluna não diferem significativamente entre si em nível de 5\% de probabilidade, pelo Teste Scott-Knott. 
(2011), a firmeza da polpa está relacionada à resistência ao transporte e à vida de prateleira dos frutos.

O maior teor de sólidos solúveis foi encontrado nos frutos da cultivar 'Minasul', com $12,60^{\circ}$ Brix (Tabela 1), valor inferior ao máximo encontrado por RAMOS \& LEONEL (2008), avaliando 12 cultivares de pêssegos na região de Botucatu-SP, que obtiveram frutos cujo maior teor de sólidos solúveis foi de $16,3^{\circ}$ Brix. De acordo com CLARETON (2000), para que o pêssego tenha boa qualidade, é necessário que tenha teor de sólidos solúveis acima de $11^{\circ} \mathrm{Brix}$, sendo que teores abaixo de $10^{\circ}$ Brix, geralmente, não são aceitos pelos consumidores.

A acidez titulável variou consideravelmente, sendo os menores teores obtidos nos frutos das cultivares 'Belvedere' (0,43\%), 'Coral' (0,44\%) e 'Rubimel' (0,41\%) e o maior teor nos frutos da cultivar ‘Topázio’ (0,76\%). ALMEIDA (2006) descreve que frutos de pessegueiro marcadamente mais ácidos apresentam baixa aceitação tanto pelo mercado atacadista como pelo consumidor final.

A cultivar 'Belvedere' teve maior valor para ratio $(25,56)$, no entanto, não diferiu estatisticamente das cultivares 'Coral', 'Rubimel e 'Talismã'. Por outro lado, frutos da cultivar 'Baronesa' apresentaram o menor valor (11,66). MATIAS et al. (2011), avaliando frutos de 17 famílias de pessegueiro na geração $F_{2}$ em Araponga/MG, observaram grande variação nos valores de ratio (de 16,60 a 70,91), em comparação à variação encontrada no presente estudo. Os altos valores de ratio obtidos pelos citados autores estão associados principalmente à baixa acidez dos frutos, cuja média das famílias foi de 0,48\%.

Os valores de vitamina $C$ variaram de 7,58 a 19,47mg.100g-1 , sendo que 'Aldruigui' apresentou o menor teor e 'Flordaprince' o maior teor de vitamina C (Tabela 1). Esses valores são superiores aos verificados por SEGANTINI et al. (2012), os quais caracterizaram polpa de pêssegos produzidos em São Manuel/SP e relataram valores de vitamina $C$ entre 7,95 e 17,31 mg $100 \mathrm{~g}^{-1}$, nas cultivares de pêssego de polpa amarela avaliadas. De acordo com os mesmos autores, em frutas, além de variar entre cultivares, os teores de vitamina C podem variar em função de outros fatores, como tratos culturais e diferentes locais de cultivo.

Os teores de carotenoides variaram de 0,33 e $1,40 \mathrm{mg} 100 \mathrm{~g}^{-1}$, nos frutos das cultivares 'Coral' e 'Aldrigui', respectivamente, valores bem superiores aos observados por SEGANTINI et al. (2012), que

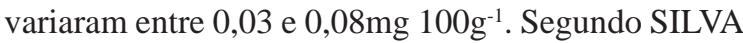
et al. (2009), uma mesma variedade pode apresentar diferenças na composição química de seus frutos, dependendo da metodologia de análise utilizada, do estágio de maturação do fruto quando colhido e da região produtora. Isso reforça o potencial da Zona da Mata mineira no tocante à produção de pêssegos de boa qualidade, uma vez que os carotenoides são os pigmentos responsáveis pela coloração amarela da polpa e, de acordo com FARAONI et al. (2008), tratando-se de polpas e de produtos elaborados a base de polpa de fruta, a cor influencia na qualidade e é um importante caráter utilizado no controle do processamento desses produtos.

As cultivares 'Cerrito', 'Minasul' e 'Olímpia’ apresentam, no geral, maior massa e diâmetros de frutos. Em relação aos atributos de qualidade, as cultivares que se destacam são 'Belvedere', 'Rubimel', 'Coral' e 'Talismã', apresentando melhor balanço entre sólidos solúveis e acidez. 'Baronesa' e 'Flordaprince' apresentam os maiores teores de vitamina C e 'Aldrigui' e 'Elberta' destacam-se em relação aos teores de carotenoides.

\section{AGRADECIMENTOS}

À Coordenação de Aperfeiçoamento de Pessoal de Nível Superior (CAPES) (PNPD- 23038.007982/2010-19 AUXPE 3025/2010), Conselho Nacional de Desenvolvimento Científico e Tecnológico (CNPq) (Bolsas de Produtividade e Doutorado) e Fundação de Amparo à Pesquisa do estado de Minas Gerais (FAPEMIG) (Demanda Universal 2011), pelo apoio financeiro.

\section{REFERÊNCIAS}

ALBUQUERQUE, A.S. et al. Avaliação de cultivares de pêssego e nectarina em Araponga, Minas Gerais. Revista Ceres, v.47, n.272, p.401-410, 2000. Disponível em: <http://www.ceres.ufv.br/ CERES/revistas/V47N272P03600.pdf>. Acesso em: 24 jul. 2012.

ALMEIDA, G.V.B. Características qualitativas de pêssegos produzidos em Paranapanema, SP, safra 2005, e sua valoração no mercado atacadista de São Paulo. 2006. 66f. Dissertação (Mestrado em Agronomia) - Curso de Pós-graduação em Agronomia, Universidade Estadual Paulista, SP.

AOAC. (ASSOCIATION OF OFFICIAL ANALYTICAL CHEMISTS). Official methods of analysis of the Association of Official Analytical Chemists International. 16.ed. Washington, 1997. V.2, p.37-10, 42-2, 44-3, 45-16.

CLARETON, M. Peach and nectarine production in France. Trends, consumption, and perspectives. In: PRUNUS BREEDERS MEETING, 2000, Pelotas, RS. Summaries... Pelotas: Embrapa Cliama Temperado, 2000. p.83-91. (Documentos, 75).

CRUZ C.D. Programa genes-versão Windows-Aplicativo computacional em genética estatística (Versão 2007). Viçosa: UFV, 2006.

FARAONI, A.S. et al. Efeito dos métodos de conservação, tipos de embalagem e tempo de estocagem na coloração de polpa de manga 'Ubá’ produzida em sistema orgânico. Revista Ceres, v.55, n.6, 
p.504-511, 2008. Disponível em: <http://www.ceres.ufv.br/ceres/ revistas/V55N006P35808.pdf>. Acesso em: 24 jul. 2012.

GIL, M.I. et al. Antioxidant capacities, phenolic compounds, carotenoids, and vitamin C contents of nectarine, peach, and plum cultivars from California. Journal of Agricultural and Food Chemistry, v.50, n.17, p.4976-4982, 2002. Disponível em: <http://pubs.acs.org/doi/full/10.1021/jf020136b>. Acesso em: 24 jul. 2012. doi: 10.1021/jf020136b.

LEONEL, S. et al. Produção e qualidade dos frutos de pessegueiro e nectarineira em clima subtropical do estado de São Paulo. Revista Brasileira de Fruticultura, v.33, n.1, p.118-128, 2011. Disponível em: <http://www.scielo.br/scielo.php?pid=S010029452011000100017\&script=sci_abstract\&tlng=pt $>$. Acesso em 31 jul. 2012. doi: 10.1590/S0100-29452011005000043.

LICHTENTHALER, H.K. Chlorophylls and carotenoids: pigments of photosynthetic biomembranes. Methods in Enzymology, v.148, p.349-382, 1987.

MATIAS, R.G.P. et al. Qualidade de pêssegos provenientes de plantas selecionadas para capacidade de brotação. Revista Brasileira de Agricultura Sustentável, v.1, n.2, p.45-49, 2011.

MONTES, S.M.N. et al. Características produtivas, físicas e químicas de frutos de cultivares de pessegueiros sobre dois porta-enxertos no oeste do Estado de São Paulo. Revista Brasileira de Fruticultura, v.30, n.4, p.1065-1070, 2008. Disponível em: <http://www.scielo. br/scielo.php?script=sci_arttext\&pid=S0100-29452008000400037>. Acesso em: 02 abr. 2013. doi: 10.1590/S0100-29452008000400037.

RAMOS, D.P.; LEONEL, S. Características dos frutos de cultivares de pessegueiros e de nectarineira, com potencial de cultivo em Botucatu, SP. Bioscience Journal, v.24, n.1, p.10-18, 2008. Disponivel em: <http:// www.seer.ufu.br/index.php/biosciencejournal/article/view/6774/4471>. Acesso em: 24 jul. 2012.

SEGANTINI, D.M. et al. Caracterização da polpa de pêssegos produzidos em são Manuel-SP. Ciência Rural, v.42, n.1, p.52-57, 2012. Disponivel em: <http://www.scielo.br/scielo. php?pid=S0103-84782012000100009\&script $=$ sci_arttext $>$. Acesso em: 10 jul. 2012. doi: 10.1590/S0103-84782012000100009.

SILVA, D.F.P. et al. Caracterização de frutos de 15 cultivares de mangueira. Revista Ceres, v.56, n.6, p.783-789, 2009. Disponível em: <http:/www.ceres.ufv.br/ceres/revistas/V56N006P03809.pdf>. Acesso em: 24 jul. 2012.

WAGNER JÚNIOR, A. et al. Seleção de progênies e genitores de pessegueiro com base nas características dos frutos. Revista Brasileira de Fruticultura, v.33, n.1, p.170-179, 2011. Disponível em: <http:/www.scielo.br/scielo.php?pid=S010029452011000100022\&script=sci_arttext>. Acesso em: 24 jul. 2012. doi: 10.1590/S0100-29452011005000044. 